\title{
ABISMO ENTRE O TUDO E O NADA - A ETNOLOGIA DE OKAMOTO TARO
}

Ryuta Imafuku

É simplesmente avassaladora a presença de Okamoto Tarô no filme de 14 minutos, em $16 \mathrm{~mm}$, intitulado Homenagem a Marcel Mauss: Okamoto Taro, dirigido por Jean Rouch, conhecido por seus trabalhos de vanguarda na França, no campo da antropologia visual. Foi muito forte o impacto que me causou a fala de Okamoto - e aqui vou designar por fala, um termo do linguajar cotidiano, todo o conjunto de sua impressionante forma de expressão - que se manteve inalterável do princípio ao fim. Okamoto respondia pronta e vivamente às perguntas formuladas pelo entrevistador Rouch com a câmera em punho, e suas palavras, acompanhadas de passos, gestos, olhares e expressões que mudavam em detalhes surpreendentes, transcendiam o mundo do significado de superfície da língua francesa, conquistando uma instância suprema na qualidade da voz que revela a força e a profundidade próprias do ser que é Okamoto Taro. Na cadeia pura e agressiva dessa voz, ressoava continuamente em meus ouvidos o eco de tous ("tudo").

O filme começa com os dois caminhando pelas ruas de Aoyama em direção ao ateliê de Okamoto. Nessa parte inicial, Rouch indaga, como numa introdução apropriada para um documentário, como Okamoto, que é pintor, foi assistir em Paris às preleções do eminente etnólogo Mauss. Radical é a resposta prontamente dada por Okamoto a essa pergunta ortodoxa. "Não há sentido na própria distinção em pintura ou etnologia. Assim como Mauss, eu sou filósofo, sociólogo, etnólogo, tudo..." Neste momento, o forte desígnio de Okamoto de nos impor a palavra tous contra a convenção de quaisquer

* Professor Visitante da Universidade Sapporo, junto ao Programa de Pós-Graduação de Língua, Literatura e Cultura Japonesa da FFLCH. O presente artigo baseia-se numa palestra proferida no Centro de Estudos Japoneses da USP, em 23 de agosto de 2000. 
idéias preestabelecidas e conceituações, inflama em seu olhar vivo. Em seguida, as palavras de Okamoto fluem caudalosas. O quanto as preleções de Mauss foram frutíferas para ele quando jovem. Em particular, o quanto foram decididamente reveladoras para redescobrir a relação entre ele e o passado da humanidade... Depois, já conduzido ao jardim do ateliê, Rouch formula a Okamoto uma outra pergunta, em certa medida, de praxe: "O senhor está falando apaixonadamente de Mauss mas agora não se dedica à etnologia mas à pintura e à escultura, não é verdade?" Prontamente, o mesmo "tous, tous, tous, tous, tous, tous!!!" - Okamoto responde balançando a cabeça, como se estivesse apenas esperando a deixa.

O tous seis vezes emitido, suave mas firmemente, como que para dissuadir um amigo que demora em compreendê-lo. Como o próprio Okamoto se reporta posteriormente em Memórias (publicado em Nascimento da Magia), provavelmente quis embutir nessa surpreendente cadeia de seis tous sua decisão de viver como um artista "humanamente completo" Não se deve viver como um profissional dividido em compartimentos menores como pintor, escultor ou etnólogo, não há sentido em viver "se não se vive como um todo cósmico" Portanto, a semântica do tous de Okamoto não se refere somente a "tudo" em seu sentido literal que remove as divisões institucionais, mas significa também o projeto extraordinário de interiorizar em seu cérebro e corpo o "todo cósmico" que gira como um gigantesco espírito a vibrar.

O filme vai sendo marcado pela performance de Okamoto que frauda o desígnio de Rouch em tentar orientá-lo a falar de suas reminiscências de Mauss. Okamoto vai explicando cada uma das estranhas peças expostas no jardim de seu ateliê. Peças intituladas Homem Árvore, Sol da Tarde, Cadeira que Recusa o Sentar-se, o quadro inacabado intitulado Voar pelo Céu tomam todo o espaço. E caminhando pelos intervalos entre essas obras, Okamoto defende e reafirma vigorosamente sua própria existência. As perguntas sóbrias de Rouch como etnólogo, historiador de artes que indagam sobre as relações de Okamoto com os discípulos de Mauss como Marcel Griaule, Michel Leiris, acabam sendo claramente anuladas por uma fria não-reação. Neste momento é preciso pensar sobre a realidade de sua própria existência mais do que exaltar outrem. A cena é iluminada apenas pela marcante presença de Okamoto que, de modo categórico, afirma "Eu tenho que existir", como que a se desvencilhar das perguntas enfadonhas de Rouch que só buscam fazê-lo falar de Mauss.

Passando ao interior do ateliê, diante da foto A Torre de Sol, Okamoto começa a tecer críticas sobre os valores do modernismo ocidental e do gosto japonês formal que dominam de forma latente o senso estético japonês. A tradição esvaziada não existe em parte alguma. É o momento em que se passa a ser livremente discorrida a tese original de Okamoto sobre a criação, segundo a qual é a tradição que deve ser criada. Comentando, com sarcasmo, que rótulos já não têm mais nenhuma importância, em resposta à cortês intervenção de Rouch que dizia não ser "à japonesa" mas "à Okamoto"...

Passa-se à última cena, ao lado do sino, e novamente aquele tous irrompe da boca de Okamoto. Ele bate com toda a força o estranho sino de mais de 30 arestas, com mandaras de toque pessoal gravadas e, certificando-se de suas ressonâncias com uma expressão marota, Okamoto que falava de "sua criação" volta os olhos repentinamente e começa a repetir outra vez "tous, tous, tous tous..." Esse "tudo" é etnologia. Isso é 
criação, é ressonância, consonância. E sobrepondo-se aos ecos metálicos do sino, tive a impressão de ouvir Okamoto dizer: "Este é o som da etnologia"

Deixando Okamoto que, com uma expressão feliz, continua batendo "o som da etnologia" num canto do jardim, a câmera deixa o local. Esta se vira à saída do ateliê e grita com a voz de Rouch "Até logo, até uma outra vez!" A voz grossa de Okamoto, já fora das lentes, responde: “Até uma outra vez, em Paris!”... O filme Homenagem a Marcel Mauss: Okamoto Taro termina nesta cena.

O projeto deste documentário Homenagem a Marcel Mauss, de autoria de Rouch, começou com a idéia de extrair a figura humana e a herança dos trabalhos de Mauss a partir de reminiscências de alunos e discípulos que receberam seus ensinamentos. Entre 1969 e início da década de 70, quando foi organizada e publicada a coletânea de artigos de Mauss, teve lugar na França um movimento de revalorização do autor, contexto em que nasceu a idéia do filme de Rouch. Dentro desse projeto, estavam ainda previstas entrevistas com Lévi-Strauss, com Michel Leiris, que acabaram não se concretizando, e, além deste trabalho com Okamoto concluído, apenas ficaram prontas, em 1977, as entrevistas com o sociólogo e teólogo Marcel Lévi e com a antropóloga e colaboradora de Rouch na pesquisa com o povo dogon, Germaine Dieterlen. Assim, eu diria que a entrevista com Okamoto, que atuava como artista no Japão, constitui um fato singular dentro desse quadro.

De qualquer forma, do ponto de vista do objetivo do projeto que era buscar a pessoa e o pensamento de Mauss através de depoimentos de terceiros, temos que admitir que o quadro de Okamoto Taro foi um fracasso. Como foi dito anteriormente, as respostas às perguntas dirigidas por Rouch foram freqüentemente desviadas com leveza para uma problemática do próprio Okamoto, tornando-se em vão o esforço de Rouch em retomar o rumo da conversa e ganhando espaço a pretensão de Okamoto em fazer sugestões mais e mais livres de idéias... Tem lugar neste filme apenas o roteiro de Okamoto, que teria começado a falar da etnologia de Mauss mas de repente começa a discorrer apaixonadamente sobre sua própria poesia e verdade.

No entanto, analisando-se de um ponto de vista distanciado do indivíduo Mauss, tratam-se de imagens da performance e da narrativa de um indivíduo fascinante. A presença marcante de Okamoto, repetindo "tous, tous, tous..." que mais parece um signo, acaba magistralmente transformando a "cena" em algo dele próprio, através de uma extraordinária autoconfiança, uma enigmática intuição e uma encantadora perícia. Isso, sim, poderia ser a única e maior essência estética do filme Homenagem a Marcel Mauss: Okamoto Taro. E quando nos deparamos com a encenação de Okamoto, que eu diria misteriosa e até mesmo espirituosa, em que ele, batendo o sino por ele mesmo construído, procura o "som da etnologia" em sua complexa ressonância, pressentimos o desmoronar da imagem cristalizada que se tem da "etnologia" enquanto ciência. Isso nos mostra que a "etnologia" de Okamoto, apesar de beber na fonte de Mauss, transcende de longe o nível de uma cabal compreensão na perspectiva usual de um historiador cultural.

Esse trabalho de Rouch de tentar descobrir Mauss através de Okamoto e que resultou em "fracasso" no que diz respeito à imagem, pode facilmente encontrar uma perspectiva desde que se analise a obra de Okamoto rastreando seus textos. 
Fica claro, antes de mais nada, que os termos conceituais e estéticos encontrados nas obras de Okamoto são basicamente de Mauss. Termos bataillanos como "explosão, fervura, tremor" originaram-se da etnologia de Mauss e se tornaram conceitos largamente usados pelos membros do Collège de Sociologie, a começar por Bataille. E o termo básico "magia", o ponto de partida conceitual do pensamento de Okamoto, é o que melhor comprova ser ele um discípulo direto de Mauss.

Em sua obra O Nascimento da Magia, Okamoto afirma de forma mais contundente que "a arte é magia" É importante notar que o conceito de magia (e outros adjacentes como reza mágica, feitiçaria, maldição), que ele mais intuitivamente utilizou, foi também o conceito central da etnologia que Mauss discute e teoriza em sua Esboços de uma Teoria Geral da Magia (1903) e que mais tarde, em sua obra mais significativa Ensaio sobre o Dom (1924), analisa tendo como exemplos concretos a cultura das ilhas melanésias e de tribos indígenas do noroeste americano. Mauss contestava a tese antropológica oitocentista, representada por Frazer, que definia a magia como uma forma da simpatia do homem em virtude de sua formalidade ritual e foi um dos que primeiro defendeu a postura de estimular pesquisas sobre a magia sob a perspectiva de um "estudo de uma força coletiva" que age universalmente nas sociedades humanas, tratando a posição social do mágico, as várias facetas do rito da magia, as diversas manifestações mágicas e a simbologia da magia.

Nesse sentido, xamãs e mágicos são seres privilegiados, donos da chave do segredo que conduz a uma totalidade universal da visão de mundo dos homens. De fato, em seu influente artigo As Técnicas do Corpo, Mauss desenvolve uma tese fascinante sobre o corporal mágico do homem e a geração social de suas técnicas do corpo, considerando as técnicas mágicas do corpo tais como o transe e a possessão um mecanismo que domina, que conduz a realidade coletiva da sociedade. Em outras palavras, o mágico é um tipo de personalidade singular que é gerada pela sociedade e é necessária à sociedade, apesar de exibir um poder individual especial.

Quando Okamoto Taro brada e escreve a palavra "magia" atrás do uso que ele faz deste conceito, sempre sinto uma espécie de determinação inexorável de Okamoto artista em tentar incorporar a personalidade social que é o mágico. Assim ele escreve na introdução de Nascimento da Magia.

A arte é magia.

Apresenta de forma mais clara o caos primário da vida humana. Assim como existe o espelho para refletir a figura do homem, é a arte que enfeitiça tomando o espírito pelo reverso.

No entanto, negar até o fím a compreensão é a essência da arte. Realmente, o artista impõe a outrem o seu mundo, tem um intenso dinamismo de conquista, uma vontade de poder. É o romantismo do artista.

Entretanto, esconde-se uma grande contradição nesse imperialismo. Porque, na realidade, tem também o desígnio de não permitir que ninguém o compreenda. [...]

O entusiasmo em se fazer compreendido e, ainda mais forte, o desígnio de romper a comunicação.

Se eu enfatizo que o artista não deve ser amado, que tem que ser detestado, não é nenhum paradoxo, apenas designei tal perigo em uma linguagem cotidiana clara e simples. 
A surpreendente As Técnicas do Corpo do mágico que se manifesta enfeitiçandose a si mesmo, primeiro, para se lançar dentro de um profundo mistério supranatural. Okamoto assim intuía profundamente que tal mecanismo comportava, como resultado, a via da incompreensão e da ruptura da comunicação social. Assim como as sociedades primitivas absorvem o contexto em que se gera a magia, Okamoto buscou a relação entre a sociedade contemporânea e a arte na dinâmica de contraposição entre compreensão e isolamento.

Tal postura de Okamoto me evoca de imediato a seguinte passagem de Esboço de uma Teoria Geral da Magia, de Mauss.

Os gestos do mágico ocorrem às ocultas, suas palavras são difíceis de serem apreendidas. Os curandeiros, os algebristas que procedem às curas diante dos familiares do doente, murmuram silenciosamente as rezas, seus atos são realizados às ocultas e são encobertos por um êxtase real ou falso. Assim, os mágicos se mantêm isolados mesmo nos meios sociais, quanto mais em meio a selvas profundas. Eles dificilmente se freqüentam, mesmo entre pares. $O$ isolamento, assim como o segredo, é um perfeito marco da essência do rito mágico. O rito mágico é sempre um ato individual ou o ato de vários indivíduos que agem individualmente, e ato e atuante são envoltos pelo mistério.

Como fica claro nessas comparações, se quisermos enfocar a assimilação feita por Okamoto do conceito maussiano de "magia", temos que valorizar, não a coincidência superficial do uso que ambos fazem do termo, mas a leitura e interpretação dada por Okamoto ao status da capacidade individual do mágico, definida como um ser social por Mauss, transpondo-o ao nível de sua própria posição social como artista. Dessa forma, certamente Okamoto se asseverava que a "etnologia" de Mauss revivia dentro deste seu ato de criação artística e ideológica. Como vou me referir posteriormente, o pensamento etnológico de Mauss apresentava o maior e mais rico leque de possibilidades nas atividades de transposição do saber, quando era adaptado para outras áreas tais como a poesia, as artes plásticas, a filosofia corporal, a teologia.

No entanto, o cerne ideológico que o texto de Okamoto compartilha com a etnologia de Mauss não se restringe ao uso do termo maussiano, mas em sua reflexão profunda sobre o conceito de "totalidade" É do conhecimento de todos que o conceito de "fato social total" se encontra na base do pensamento de Mauss. Para ele, a essência total de uma sociedade se encontra na expressão simbólica de sua instituição social, de seus costumes, aí consideradas desde as atividades coletivas de sociedades não desenvolvidas tais como a magia, ritos religiosos, formas de troca, até os domínios culturais tidos como mais individuais como males psíquicos, representações emotivas.

Esse conceito de "fato social total" apresentado em seu Enasio sobre o Dom, publicado de 1923 a 1924 no Année Sociologique e que exerceu forte influência em Paris nos anos 30, época da formação intelectual de Okamoto, é um conceito que toma como "social" e "coletivo" o espaço em que se cria e adquire significado a experiência de vida de cada indivíduo, e que foi usado para apresentar a tese de que o social se torna de fato "realidade" quando é integrado ao sistema total. Enfocando a prática do dar e os ritos especiais de dissipação dos índios do noroeste americano e melanésios, Mauss 
descobriu que isso perpassava todos os aspectos do princípio social que integra, enquanto "fato social total", toda a instituição social secionada em partes como religião, economia, direito.

A idéia maussiana de "fato social total" salientou a todos a importância de se observar os comportamentos do ser total, não secionados em diferentes capacidades. Ao mesmo tempo, incitou cientistas e artistas a buscarem a totalidade das capacidades de vida do homem, impossível de ser desvendada pelo enfoque de um de seus vieses. Para mim, Okamoto apreendeu essa mensagem mais nuclear e universal de Mauss da forma mais contundente e também mais criativa do que ninguém, nisso investindo seu cérebro e corpo. Assim, por exemplo, na introdução de sua obra A Força Mágica do Belo (1971), fala do impacto avassalador e ao mesmo tempo fundamental causado pela forma do inugsuk dos esquimós canadenses, resultado de uma fantástica sobreposição de pedras - Mauss também já manifestara sua admiração incontinente pela cultura esquimó em seu As Variações Sazonais das Sociedades Esquimós, publicado em 1906 - e critica a triste condição dos "objetos de arte" que se vêem asfixiadas em espaços limitados. A vida humana existe sempre como uma totalidade, "deveria se inflar, transbordar em toda sua extensão" mas os homens acabam dela extraindo uma parte e a definindo, formalizando, embriagados, como "arte". Para fugir de tal segmentação, Okamoto considera essencial "uma visão humana total" e assim se pronuncia.

A sensação do absoluto que hoje vivemos. Quando isso e o simbólico que aflui do âmago da história, o conceito principial de vida aí latente, se tocam, há algo que aflora com uma viva reação. É isso que eu busco.

$\mathrm{Na}$ cultura humana havia, desde as épocas primitivas, ritos, festas. Havia canto, havia dança. Havia comida, vida, trabalho, guerra e inúmeras outras atividades. Impossível definir qual o mais importante, qual o menos importante. Tudo se entrecruza e constitui um sistema de vida, um organismo. O que restou como objeto - a cor, a forma - eram partes desse todo vivo.

A parte final desse trecho é a própria visão de mundo que Mauss desvendou e propôs. Em seu Enasio sobre o Dom, ele denomina "totalidade orgânica (tous) a realidade total vivida pela sociedade" Tous acaba se tornando a palavra mágica para se reavivar Mauss, através da voz e do corpo de Okamoto. O fato de Okamoto ser criativo reside em, além de proceder a uma exposição racional da tese cristalizada de Mauss como se vê no começo do trecho citado, não se apoderar e reutilizar simplesmente a herança maussiana mas em defrontá-la diretamente com sua própria problemática atual como artista e pensador, daí extraindo com energia o princípio de seu pensamento, de seus atos conscientes. Um artista cuja forma de expressão é, em princípio, criar coisas, ultrapassa a segmentação das coisas deixadas como marcas da cultura antropológica e procura refletir com acuidade sobre como se aproximar da visão do homem total... É essa a sua luta consciente que faz de Okamoto um exemplo particular de discípulo intelectual e espiritual de Mauss. Se me permitem uma consideração, eu diria que os leitores de Okamoto costumavam interpretar a parte inicial do texto citado como uma expressão muito idiossincrática sua. Faz-se necessária uma análise mais atenta sobre o sentido que um texto assim tão intuitivo seja escrito junto a outro tão racionalmente claro. Sobre a luta e o ritmo do diálogo no texto... 
As considerações sobre o inugsuk ainda se desenvolvem até o limite. Inugsuk é uma das poucas provas deixada na terra pela cultura étnica que não se prende ao estético ou ao representativo das coisas extraídas da totalidade da vida. Apesar de ser apenas um vestígio, é suficiente para evocar uma imagem de sonhos perdidos no passado infinito. O sentido real das coisas não seria o que brilha quando mostram algo do tamanho do mundo, maior do que a própria coisa? O valor da coisa em si não é nada mais nem menos do que ela existir como vestígio de alguma outra coisa. Assim escreve Okamoto.

$\mathrm{O}$ absoluto que existe enquanto objeto vive no momento em que sua vida se abre junto com o espírito humano. E basta. Assim testemunha a própria "relíquia"

Quão grandes e nobres não foram as culturas inexoravelmente desaparecidas!

Mas quero avançar mais um passo. Não que as coisas tenham sido criadas e depois perdidas mas, sim, há o clima espiritual que aposta a vida no "vazio" onde nada existe, há essa extensão.

Eu particularmente sinto uma reação quando, como japonês, me defronto com essa sensação de vazio. Um domínio cultural como este certamente existe neșse mundo.

Não posso deixar de ver nesse texto, que aparentemente foi escrito de forma ingênua, a problemática mais essencial ou até mesmo uma espécie de princípio de criação em que Okamoto investiu sua mente e seu corpo. Não se trata de buscar o reflexo real da totalidade da vida na cultura material tais como utensílios cotidianos, máscara ou produtos arquitetônicos, nem buscar o fenômeno social total através de monumentos da cultura espiritual tais como ritos, festas, mitos, mas trata-se de intuir a fonte da força que agita a própria existência no vazio do "nada" do assim dito vestígio cultural... Criar um espaço transparente e cheio de tensão onde o "tudo" é intermediado pelo "nada", a "totalidade" é despertada por via do "vazio"...

Okamoto se impressiona fortemente ao encontrar o mote para essa força em Okinawa. Ele descreve fluente e magistralmente o impacto causado pelo "vazio" chamado Okinawa em sua obra Ensaio Cultural sobre Okinawa - o Japão Esquecido. No capítulo intitulado "A Vertigem do "Nada Existir" ", descreve o profundo impacto que teve, ao visitar o recinto sagrado utaki na ilha Kudaka, com o "nada existir" excessivamente forte do espaço em um canto do bosque onde descem seus deuses. Para Okamoto, a vertigem deste "nada existir" se acercava de sua essência inexorável de japonês de forma solene e, antes de mais nada, aguda. A indescritível emoção por ele sentida ao saber que a pedra colocada displicentemente num canto vazio do utaki era o incensário para dirigir a prece aos deuses traz-lhe à mente a seguinte reflexão.

$\mathrm{O}$ começo é imaculadamente simples. $\mathrm{O}$ bosque esplendidamente tranqüilo. $\mathrm{O}$ recinto sagrado, assim definido por mensagem divina, é o centro da vida tribal. Neste local recôndito, baixa furtivamente uma energia sobrenatural. Não é possível pensar numa força motriz da vida deles sem o elo com esta energia, sem o amparo dela.

Uma árvore imponente. É o caminho escolhido por deus, seu médium. O homem colocou uma pedra nesta ponte divina. Ela é a chave, o centro da vontade do homem que apela para um ser invisível.

Uma árvore e uma pedra da natureza, são elas a via principial entre deuses e o homem. 
E aqui gostaria de deixar enfatizadas duas palavras. Uma é "desígnio" Essa via para o misterioso colocada pelo homem, que é pedra e também desígnio, era o gesto mais pujante da criação concebida por Okamoto. A teoria e a visão de mundo podem dar sentido a um comportamento somente quando têm esse enérgico "desígnio" como médium. A outra é a idéia de "principial". Seu sentido não tem uma conotação temporal voltada para o passado como as palavras "primitivo" ou "originário" Trata-se de uma palavra que expressa um arquétipo existente no princípio das coisas e que dá forma a todas as criações, assim como o mito apresenta aos homens uma visão sincrônica de mundo, voltando eternamente ao "agora" Assim sendo, a descoberta em Okinawa também mostra o "princípio" da atividade criadora de Okamoto. É impulsionar o desígnio que ele investe em sua criação artística, criando coisas assim como se coloca displicentemente uma pedra, enfrentando a alegria e a dor do "nada existir" sem se aprisionar com a materialidade ou a formalidade de sua obra.

Existe uma chave essencial para se pensar a criatividade de Okamoto nesse seu projeto de se estabelecer uma ponte entre o "tudo" herdado de Mauss e sua simpatia pelo "nada" arquetípico que encontrou nos ermos do arquipélago japonês. Considerase habitualmente que um fundo e intransponível abismo se interpõe entre o tudo e o nada. No entanto, a presença de Okamoto manteve um forte brilho por seu inquebrantável e pujante desígnio de dirigir seu corpo e mente à majestosa cadeia da experiência das sociedades humanas que liga o tudo e o nada. E se admitirmos a existência de uma "etnologia" principial com matizes de "desígnio", ela é uma das grandes possibilidades da etnologia herdada de Mauss por Okamoto.

Como já me referi anteriormente, dentre os discípulos de Mauss existiram alguns pensadores singulares que nem sempre seguiram a linha ortodoxa da "antropologia" ou da "etnologia" e, dentro de um apelo de sua "realidade" inexorável, reformularam intencionalmente os ensinamentos de Mauss, elevando-os a uma reflexão criativa que perpassa toda sua expressão. Não poderia deixar de fazer referência ao grupo de discípulos heterodoxos de Mauss, diferentes dos cientistas que representam a linhagem intelectualista da antropologia, da arqueologia tais como Lévi-Strauss, Louis Dumont ou André Leroi-Gourhan. Um deles é o escritor Michel Leiris que foi aluno de Mauss e um dos membros centrais do "Grupo de Estudos Sociais" do qual fizeram parte Bataille, Caillois e, mais tarde, o próprio Okamoto. Ou então, Maurice Leenhardt que, depois de aprender etnologia com Mauss, tornou-se missionário e foi para a tribo dos kanaca na Nova Caledônia, onde não se dedicou à catequisação dos nativos mas, sendo catequisado pela visão dos kanaca, prevê a ruína ideológica da catequese européia e brilha ao publicar Do Kamo, uma obra singular sobre a integração cósmica da "personalidade" humana. Foi também discípulo de Mauss o antropólogo Roger Bastide que, tendo mergulhado no mundo do candomblé, a religião possessória dos negros brasileiros, experienciou ele próprio o transe e, confrontando a visão cósmica relacionada ao êxtase e à embriaguez aí encontrados com a criatividade poética afro-brasileira, foi entrando no domínio da literatura.

Desnecessário se torna reafirmar que Okamoto Taro faz parte dessa linhagem como mais um de seus marcos singulares. Talvez possamos afirmar que a "etnologia" de Mauss continua, em um certo sentido, apresentando suas mais ricas possibilidades 
pelo fato de viver integralmente como esse espírito criativo, de ser renovado por uma atitude de desígnio.

Nesse sentido, o filme Homenagem a Marcel Mauss - Okamoto Taro, de Jean Rouch, não foi necessariamente um fracasso. Ao contrário, está transmitindo da forma mais eloqüente o ensinamento de Mauss que vive magistralmente transposto na personalidade que é Okamoto Taro, isto é, como uma radical fala do desígnio de Okamoto que permeia todo o filme. Se voluntário ou não, o documentário que procurou reconstituir Mauss através de depoimentos de seus discípulos acabou evocando a cena do princípio de que se origina a etnologia maussiana, nas palavras e no corpo de Okamoto.

De repente me vem à memória uma cena impressionante do filme O Mestre Louco (1954), obra-prima do antropólogo visual Jean Rouch. Tendo transportado a câmera até o rito possessório chamado hauca, nos arredores de Acra, capital de Gana, Rouch se depara com a impressionante cena de emigrados da Nigéria que, tomados em transe pela deidade do hauca, reproduz o processo de dominação inglesa. E as imagens de Rouch, apesar de ele ser claramente um intruso de câmera em punho, apreende o olhar dos negros possuídos, desviando assim o olhar que os etnólogos europeus buscavam. Pelas imagens de Rouch, somos levados a assistir ao desmoronar da relação até então existente entre Europa e África, com apoio na câmera que invadiu o rito de hauca.

Não teria ocorrido o mesmo com este documentário Homenagem a Marcel Mauss? Não se trata de ver como uma disciplina européia denominada etnologia de Mauss foi herdada por Okamoto, que mora nos ermos do Oriente, mas sim de ver como Mauss foi renovado como pensamento e ato totais de Okamoto, um artista japonês. É isso que as imagens de Rouch nos transmitem. A partir dessas imagens, a relação entre Europa e Japão também nos parece inesperadamente revertida.

Nesse efeito inesperado, começa a se vislumbrar a verdade de Okamoto como artista. Ela nos mostra que nesse filme, uma obra de rara felicidade, jaz em estado latente o ponto de partida epistemológico para se pensar a paixão pela idéia e pela criação artística de Okamoto que, acercando-se da tradição "japonesa" que veio se esvaziando, procurou recriá-la com suas próprias mãos.

(Tradução de Tae Suzuki) 